\title{
Does primary-care use of the HURT questionnaire aid the reduction of headache burden? Lessons for study design from an evaluation in primary care of the Arabic version
}

\author{
Ali M Al Khathaami ${ }^{1-3}$, Danah Abo AlSamh ${ }^{3}$, Mohammed Al Jumah ${ }^{3,4}$, Nasser Alotaibi ${ }^{1-3}$, Suleiman Kojan ${ }^{1-3}$, Altaf Khan ${ }^{2}$ and Timothy J \\ Steiner ${ }^{5,6 *}$ \\ ${ }^{1}$ King Abdulaziz Medical City, Riyadh, Saudi Arabia \\ ${ }^{2}$ King Abdullah International Medical Research Centre, Riyadh, Saudi Arabia \\ ${ }^{3}$ King Saud Bin Abdulaziz University for Health Sciences, Riyadh, Saudi Arabia \\ ${ }^{4}$ Department of Neurosciences, King Fahad Medical City, MOH, Riyadh, Saudi Arabia \\ ${ }_{5}^{5}$ Department of Neuromedicine and Movement Science, NTNU Norwegian University of Science and Technology, Trondheim, Norway \\ ${ }^{6}$ Division of Brain Sciences, Imperial College London, London, UK
}

\begin{abstract}
Background: The Headache Under-Response to Treatment (HURT) questionnaire is a self-administered outcome measure designed to assess and promote effectiveness of headache management in primary care. It links responses indicative of suboptimal treatment to specific clinical actions to improve outcomes. We aimed in this study to test whether integrating HURT into assessment and follow-up in primary care in Saudi Arabia improved headache management.

Methods: With IRB approval, primary-care physicians (PCPs) were recruited from two health-care centres in Riyadh. After basic training in headache care, they were randomly assigned to either of two groups: one, with further instruction on its use, incorporating HURT into their management of patients with headache (intervention group), the other applying standard care without HURT (control group). Patients were randomised on presentation to a PCP in one or other group, thereby randomly receiving care directed by HURT or not. The primary outcome measures, estimated using the Headache-Attributed Lost Time (HALT) index, were reductions in lost productivity from paid work and household chores after 3 and 5 months' follow-up.

Results: A total of 28 PCPs participated. The study was stopped early, because of slow recruitment, after enrolment of 171 patients (84 control, 87 intervention) of 420 planned. Baseline characteristics were well matched between the groups. Patients in both groups benefited from the care they received, with no significant difference in the primary endpoint between groups after 5 months (5.2 versus 5.7 days lost; p=0.4). Patients' understanding of their diagnosis reportedly improved in the intervention group during follow-up.

Conclusion: The study failed in its purpose but delivered useful lessons for future study design in a difficult field of enquiry. First, the training we gave all PCPs, in order to balance the treatment groups, may have rendered HURT largely redundant as a management aid intended for non-experts. Second, the study demonstrates again the difficulty of conducting experiments of this sort in primary care, where interest in headache and motivation to conduct headache research are largely lacking. The second is the more intractable problem.
\end{abstract}

\section{Background}

Among adults worldwide, more than $50 \%$ have an active headache disorder, experiencing at least one headache episode per year [1]. For many, there is attendant disability [2-4]. This high proportion with health-care need mandates the management of most patients in primary care [5]. Unfortunately, the ubiquity of headache disorders is coupled with widespread lack of knowledge about them among healthcare providers (HCPs), especially those in primary care.

The Global Campaign against Headache is conducted by the UKregistered non-governmental organization Lifting The Burden (LTB) [6-8], in official relations with the World Health Organization [9]. LTB has recognized that non-specialist but competent management of headache by primary-care physicians (PCPs) would be helped not only by education but also by practical management aids [10]. One of these, developed through expert consensus and psychometric evaluation, is the Headache Under-Response to Treatment (HURT) questionnaire, a self-administered outcome measure. Used at base line and in follow-up, HURT was designed specifically for use in primary-care settings $[11,12]$. It is unique in that it not only assesses effectiveness of management but also links responses indicative of suboptimal treatment to specific clinical actions to improve outcomes [12].

${ }^{\star}$ Correspondence to: TJ Steiner, Department of Neuromedicine and Movement Science, NTNU Norwegian University of Science and Technology, Trondheim, Norway, E-mail: t.steiner@imperial.ac.uk

Key words: HURT questionnaire, headache disorders, management, outcome measure, primary care, randomized controlled trial, health policy, Saudi Arabia, Global Campaign against Headache

Received: December 06, 2019; Accepted: December 13, 2019; Published: December 16, 2019 
The eight items of HURT fall into three domains: a) Disease assessment (headache frequency and related disability), addressed by items $1-3$; b) Use, efficacy and side effects of abortive medications, and patients' perceptions about the control of their headaches (items 4-7); and c) patients' understanding of their headache diagnoses (item 8) [12]. Items 1-7 each have five response options. Those concerning frequency (items 1-4) are arranged categorically from "none" to "highly frequent"; those addressing the likelihood of certain events (items 5-7) have verbal options between "always" and "never". Item 8 has dichotomous response options ("yes" or "no"). Responses are colour-coded to aid the physician's decision making: a gradient of white to dark grey indicates what clinical actions might best improve a patient's care. When all answers lie in the white zone, no clinical action is necessary. When there are responses within the grey zones, and more so the darker the grey, actions are recommended to achieve better headache control [12].

A key purpose in the development of HURT was to create an easyto-use instrument applicable not only across clinical settings but also across different cultures and languages [12]. In the Arabic-speaking world, as elsewhere, headache is a major contributor to public ill health: an estimated 60 million native Arabic speakers are affected by headache disorders [13]. In its Arabic version, HURT has undergone psychometric validation in a multicentre primary-care study in Saudi Arabia, with test-retest reliability, responsiveness and utility demonstrated in 342 Arabic-speaking patients [14]. Here we ascertain empirically whether integrating HURT into assessment and follow-up in primary health care in Saudi Arabia improves management.

\section{Methods}

\section{Study design}

This was a randomized controlled study conducted in two primary health-care centres (PHcCs) in Riyadh, Saudi Arabia (Comprehensive Specialized Clinic in Um Al Hammam, and King Abdulaziz Housing City Clinic in Yarmouk Iskan), from November 2011 to January 2014. Intervention was at PCP- rather than patient-level.

\section{Ethics}

The study protocol was approved by the Institutional Review Board (IRB) of the King Abdullah International Medical Research Centre (KAIMRC).

The study participants included both the treating PCPs and their patients presenting with headache. PCPs were recruited by a member of the research team while patients were approached by trained research nurses in the waiting areas of the PHcCs after confirming that headache was their main complaint. In both cases, full details of the study were explained verbally and by written letter, and willing participants gave signed consent.

\section{Setting and participants}

The two participating PHcCs were under the umbrella of National Guard Health Affairs and mostly served National Guard personnel and their dependents.

All PCPs in these PHcCs were eligible. Their baseline characteristics were recorded: age, gender, year of graduation, country of training, current career rank, years of clinical experience, Arabic fluency and estimated number of headache patients seen weekly. PCPs were asked to assess their level of comfort in managing headache patients on a 3-point verbal rating scale (VRS): "very comfortable", "somewhat comfortable" or "not comfortable". To minimize inter-PCP variation in knowledge and skills, all PCPs attended a workshop on the basic principles of diagnosing and classifying headache disorders and their management according to the then-available European principles of management of common headache disorders in primary care [15].

In each PHcC, simple randomization at PCP level assigned PCPs by employee badge numbers into either the intervention arm (ie, using HURT for assessment and follow-up) or the control arm (providing standard care and follow-up without HURT). PCPs in the intervention group received further instruction, according to LTB guidance, on how to apply and interpret HURT and take the clinical actions indicated by HURT responses [12].

Patients attending either $\mathrm{PHcC}$ were eligible if they were over 18 years old, had presented with a main (but not necessarily sole) complaint of headache and were native Arabic speakers. Patients were excluded if they: a) were considered on initial evaluation to have a secondary headache disorder, headache as part of a somatization disorder or other psychiatric illness, cranial neuralgia or other central cause of facial pain; b) had significant comorbidity that would preclude the administration of HURT or prevent timely follow-up; c) showed evidence of dementia or cognitive impairment; or d) were illiterate. Eligible patients were randomized on arrival at the $\mathrm{PHcC}$ to an intervention PCP or a control PCP.

Assessment of patients, by a trained research nurse, captured baseline characteristics: age, gender, level of education, occupational status and a detailed headache history including medications they were taking to manage their headaches (abortive and preventative), their effectiveness and any side effects therefrom. Diagnoses were made by PCPs according to the International Classification of Headache Disorders (ICHD-II) [16]. Baseline assessment also included headacheattributed burden estimation using the Headache-Attributed Lost Time (HALT) index, which has five questions on lost productive or social time over the preceding 3 months [17].

\section{Management and follow-up}

From the first visit, all patients were managed by the PCPs according to the then current European principles of management of common headache disorders in primary care (standard care) [15]. In the intervention group, management was additionally informed and guided by patients' HURT responses at baseline and each followup visit. Each patient was followed by the PCP to whom he or she was initially assigned. Follow-up was planned after 3 months by clinic visit and again after 5 months by phone call, intervals chosen to provide an adequate trial of treatment and opportunity for effect measurement while minimizing learning bias arising from use of the same questionnaires more than once [18]. At the second visit, patients of both groups again completed HALT. Those in the intervention group also completed HURT, and continued treatment according to their HURT responses. Control patients were treated according to the best judgment of the treating PCPs. After 5 months, patients were contacted by a research coordinator blinded to group allocation, and again completed HALT.

\section{Statistics and analyses}

Outcome measures and sample size: Our primary outcome measures were reductions in headache burden at 3 and 5 months calculated, as a continuous measure (whole days lost), as the sum of responses to HALT items 1 to 4 (HALT score). These items estimated lost productivity from paid work and household chores. According 
Khathaami AMA (2019) Does primary-care use of the HURT questionnaire aid the reduction of headache burden? Lessons for study design from an evaluation in primary care of the Arabic version

to accepted methodology [17], we equated "less than half achieved" to "nothing achieved" in a day, and counterbalanced this by equating "more than half" to "everything".

Power calculation was based on change in HALT score: a reduction from baseline of $30 \%$ days lost was regarded as indicative of successful management. With $\alpha=0.05$ and power of $80 \%$, we estimated that the required sample size was 420 participants (210 per group). We made no allowance for losses to follow up.

HALT also allowed grading based on summed responses to items 1-5, the last item relating to lost social occasions due to headache in the preceding 3 months [17]. HALT grades I-IV respectively indicated totals of $0-5,6-10,11-20$ and $>20$ days lost. We used this as a secondary outcome measure. Other secondary measures were changes in frequency of headache attacks and use of abortive medication, and improved understanding of the headache diagnosis.

Group characteristics: Categorical data collected from PCPs and patients were analysed using descriptive statistics, and comparisons between groups used Pearson's chi-square test. Continuous variables were summarized by means and standard deviations (SDs) and compared using Student's t-test.

Analysis of outcomes: Statistical analyses were performed using SAS $^{\mathrm{Tw}}$ software version 9.2.

The longitudinal study assigned three assessments to each patient (initial, and after 3 and 5 months), with, accordingly, two intervals for outcome measurement. To account for dependency between responses due to repeated assessments, we used the generalized estimating equation (GEE) for longitudinal response data. GEE is a statistical regression method estimating change in population average over the repeated measures [19]. We applied GEEs to HALT scores, change in headache frequency, change in proportion of abortive medication use and change in patients' understanding of their diagnoses over the duration of the study. GEE results were reported with standard deviations and $95 \%$ confidence intervals (CIs). Significance was declared when $\mathrm{p}<0.05$.

\section{Results}

\section{Baseline characteristics}

All PCPs $(\mathrm{N}=28)$ from both PHcCs were included. Their characteristics are summarized in Table 1 . More than half $(57.1 \%)$ were male and most (70.8\%) were general practitioners. All were native Arabic speakers, and most (82.1\%) felt at least somewhat comfortable in managing patients with headache.

The two sites enrolled 171 patients before the study was terminated because of slow recruitment: 87 were assigned to intervention and 84 to standard care (control). None were lost to follow-up: all were included in the analyses at 3 and 5 months.

Baseline characteristics (Table 2) were well matched between the groups, except that those in the intervention group were somewhat better educated and more had sought medical help for headache in the preceding year. The control group registered fewer days lost at baseline (12.4 versus 14.8), but this difference was not significant.

\section{Outcomes}

Table 3 shows the primary outcome measure: mean reductions from baseline in productive days lost due to headache during followup. In both groups, these eventually exceeded $30 \%$, the threshold adopted a priori as indicative of effective management. After 3 months, reductions were 2.7 days $(22.4 \%)$ in the control group and $4.1(27.8 \%)$ in the intervention group $(\mathrm{p}<0.0001)$ (Figure 1$)$. After 5 months they were 7.2 days $(58.1 \%)$ versus $9.1(61.7 \% ; \mathrm{p}<0.0001)$ but with no significant difference in mean total lost days between control and intervention groups ( 5.2 versus 5.7 days; $\mathrm{p}=0.4$ ) because of the baseline imbalance.

Secondary outcome measures are shown in Table 4 . The proportions in HALT grade IV declined to zero in the control group and to $1.1 \%$ (one patient) in the intervention group. Again, this was indicative of effective management in both groups. However, there were no significant differences between groups in changes in the proportions of patients using abortive medications from baseline to the 3-month follow-up visit or from 3 months to the 5 -month follow-up ( $\mathrm{p}=0.840$ ). Also, there were no differences between groups in change in the use of preventative medication over time ( $\mathrm{p}=0.342$ ) (data not shown).

Patients treated with HURT became more likely to report an understanding of their headache diagnoses over the follow-up period: from $71.4 \%$ responding "yes" at baseline (albeit with 17 missing responses) to $90.5 \%$ at 3 months (34 missing) and $98.8 \%$ ( 0 missing) at 5 months $(\mathrm{p}<0.0001)$.

Table 1. Characteristics of treating primary-care physicians

\begin{tabular}{|l|c|}
\hline Characteristics & Values (N=28) \\
\hline Age (years) (mean \pm SD) & $40.3 \pm 10.1$ \\
\hline Gender, n (\%) & $16(57.1)$ \\
\hline male & $12(42.9)$ \\
\hline female & \\
\hline Career rank, n (\%) & $20(71.4)$ \\
\hline general practitioner (GP) & $5(17.9)$ \\
board-certified family physician & $3(10.7)$ \\
\hline resident & \\
\hline Country of training, $\mathbf{n}(\%)$ & $13(46.4)$ \\
\hline Egypt & $10(35.8)$ \\
Sudan & $5(17.9)$ \\
\hline Saudi Arabia & $15.4 \pm 9.5$ \\
\hline Clinical experience (years) (mean \pm SD) & $28(100)$ \\
\hline Arabic fluency, $n$ (\%) & $6.8 \pm 7.0$ \\
\hline Headache patients per week (mean \pm SD) & \\
\hline Comfort level in managing headache, $\mathbf{n}(\%)$ & $16(57.1)$ \\
\hline somewhat comfortable & $7(25.0)$ \\
very comfortable & $5(17.9)$ \\
\hline did not disclose &
\end{tabular}

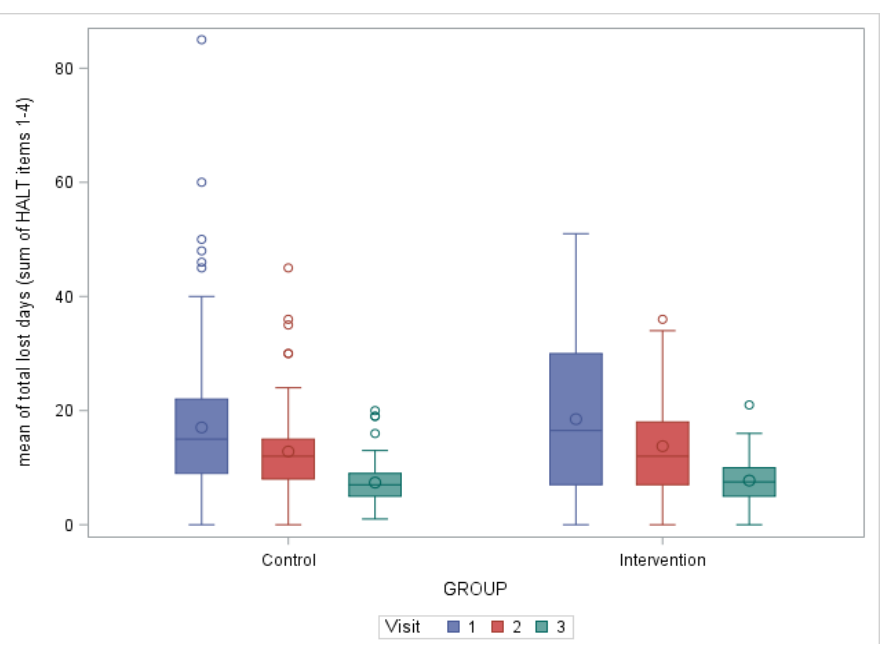

Figure 1. Change in mean total lost productive days (HALT items 1-4) over time by treatment group 
Khathaami AMA (2019) Does primary-care use of the HURT questionnaire aid the reduction of headache burden? Lessons for study design from an evaluation in primary care of the Arabic version

Table 2. Baseline characteristics of participating patients, by treatment group

\begin{tabular}{|c|c|c|c|c|}
\hline \multirow[b]{2}{*}{ Characteristics } & \multicolumn{3}{|c|}{ Values } & \multirow[b]{2}{*}{$\mathbf{p}$} \\
\hline & $\begin{array}{l}\text { Overall } \\
(\mathrm{N}=171)\end{array}$ & $\begin{array}{c}\text { Control } \\
(n=84)\end{array}$ & $\begin{array}{c}\text { Intervention } \\
(\mathrm{n}=87)\end{array}$ & \\
\hline Age (years) (mean $\pm \mathrm{SD})$ & $36.8 \pm 11.7$ & $38.1 \pm 11.5$ & $35.6 \pm 11.8$ & 0.153 \\
\hline \multicolumn{5}{|l|}{ Gender, n (\%) } \\
\hline $\begin{array}{l}\text { Male } \\
\text { Female }\end{array}$ & $\begin{array}{c}38(22.2) \\
133(77.8)\end{array}$ & $\begin{array}{l}19(20.7) \\
65(79.3)\end{array}$ & $\begin{array}{l}19(20.0) \\
68(80.0)\end{array}$ & 0.906 \\
\hline \multicolumn{5}{|l|}{ Marital status, n (\%) } \\
\hline $\begin{array}{l}\text { single } \\
\text { married } \\
\text { widowed }\end{array}$ & $\begin{array}{c}37(21.9) \\
130(76.9) \\
2(1.2)\end{array}$ & $\begin{array}{c}15(18.3) \\
67(81.7) \\
0\end{array}$ & $\begin{array}{c}22(25.3) \\
63(72.4) \\
2(2.3)\end{array}$ & 0.178 \\
\hline \multicolumn{5}{|l|}{ Education level, n (\%) } \\
\hline $\begin{array}{l}\text { less than primary school } \\
\text { primary to high school } \\
\text { university }\end{array}$ & $\begin{array}{l}27(15.8) \\
105(62.1) \\
37(21.9)\end{array}$ & $\begin{array}{l}13(15.7) \\
57(68.7) \\
13(15.7)\end{array}$ & $\begin{array}{l}14(16.3) \\
48(55.8) \\
24(27.9)\end{array}$ & 0.133 \\
\hline Education years $($ mean $\pm \mathrm{SD})$ & $8.7 \pm 4.9$ & $7.9 \pm 4.4$ & $9.4 \pm 5.1$ & 0.045 \\
\hline \multicolumn{5}{|l|}{ Employment, n (\%) } \\
\hline $\begin{array}{l}\text { unemployed/housewife } \\
\text { full-time employment } \\
\text { student } \\
\text { self-employed } \\
\text { seeking work } \\
\text { retired }\end{array}$ & $\begin{array}{l}93(55.7) \\
28(16.3) \\
24(14.4) \\
16(9.6) \\
5(2.9) \\
2(1.2)\end{array}$ & $\begin{array}{c}47(57.3) \\
14(17.1) \\
7(8.5) \\
10(12.2) \\
3(3.7) \\
1(1.2)\end{array}$ & $\begin{array}{c}46(54.1) \\
13(15.3) \\
17(19.5) \\
6(7.1) \\
2(2.4) \\
1(1.2)\end{array}$ & 0.249 \\
\hline $\begin{array}{l}\text { Sought medical help for } \\
\text { headache in preceding year, } \\
\mathrm{n}(\%)\end{array}$ & $65(38.0)$ & $23(27.4)$ & $42(50.0)$ & 0.003 \\
\hline \multicolumn{5}{|l|}{ Diagnosis, n (\%) } \\
\hline $\begin{array}{l}\text { migraine } \\
\text { tension-type headache }\end{array}$ & $\begin{array}{l}123(74.1) \\
43(25.9)\end{array}$ & $\begin{array}{l}59(72.8) \\
22(27.2)\end{array}$ & $\begin{array}{l}64(75.3) \\
21(24.7)\end{array}$ & 0.718 \\
\hline Aware of diagnosis, $\mathrm{n}(\%)$ & $20(19.6)$ & $13(25.0)$ & $7(14.0)$ & 0.161 \\
\hline $\begin{array}{l}\text { Duration of headache since onset } \\
\text { (months) (mean } \pm \text { SD) }\end{array}$ & $15.3 \pm 28.2$ & $13.0 \pm 18.7$ & $17.7 \pm 35.8$ & 0.984 \\
\hline $\begin{array}{l}\text { Headache frequency per month } \\
(\text { mean } \pm \text { SD) }\end{array}$ & $5.2 \pm 5.0$ & $4.8 \pm 4.4$ & $5.7 \pm 5.4$ & 0.650 \\
\hline $\begin{array}{l}\text { Duration of headache attacks } \\
\text { (hours) (mean } \pm \text { SD) }\end{array}$ & $1.0 \pm 0.1$ & $1.0 \pm 0.0$ & $1.0 \pm 0.1$ & 0.326 \\
\hline \multicolumn{5}{|c|}{ Intensity (without treatment), n (\%) } \\
\hline $\begin{array}{l}\text { very bad } \\
\text { somewhat bad } \\
\text { not bad }\end{array}$ & $\begin{array}{l}87(51.2) \\
65(38.2) \\
18(10.6)\end{array}$ & $\begin{array}{c}47(56.0) \\
28(33.3) \\
9(10.7)\end{array}$ & $\begin{array}{l}40(46.5) \\
37(43.0) \\
9(10.5)\end{array}$ & 0.409 \\
\hline \multicolumn{5}{|c|}{ Effect on day-to-day activities, n (\%) } \\
\hline $\begin{array}{l}\text { able to do everything as usual } \\
\text { cannot do certain activities } \\
\text { cannot do anything }\end{array}$ & $\begin{array}{l}33(19.4) \\
86(50.6) \\
51(30.0)\end{array}$ & $\begin{array}{l}16(19.0) \\
43(51.2) \\
25(29.8)\end{array}$ & $\begin{array}{l}17(19.8) \\
43(50.0) \\
26(30.2)\end{array}$ & 0.986 \\
\hline $\begin{array}{l}\text { Total days lost due to headache } \\
\text { in preceding } 3 \text { months (mean } \\
\pm \text { SD) }\end{array}$ & $13.6 \pm 12.0$ & $12.4 \pm 11.0$ & $14.8 \pm 12.4$ & 0.096 \\
\hline \multicolumn{5}{|l|}{ HALT grades, $n(\%)$} \\
\hline $\begin{array}{l}\text { I or II } \\
\text { III or IV }\end{array}$ & $\begin{array}{c}59(34.5) \\
112(65.4)\end{array}$ & $\begin{array}{l}28(47.4) \\
56(50.0)\end{array}$ & $\begin{array}{l}31(52.5) \\
56(50.0)\end{array}$ & 0.96 \\
\hline \multicolumn{5}{|l|}{ Usual treatment of attacks, $n(\%)$} \\
\hline $\begin{array}{l}\text { medication } \\
\text { traditional therapies } \\
\text { rest } \\
\text { no therapeutic measures }\end{array}$ & $\begin{array}{l}159(93.0) \\
1(0.6) \\
30(17.5) \\
2(1.2)\end{array}$ & $\begin{aligned} 81 & (96.4) \\
1 & (1.2) \\
15 & (17.9) \\
1 & (1.2)\end{aligned}$ & $\begin{array}{c}78(90.1) \\
0 \\
15(17.2) \\
1(1.2)\end{array}$ & $\begin{array}{l}0.083 \\
0.491 \\
0.915 \\
1.000\end{array}$ \\
\hline $\begin{array}{l}\text { Frequency (days) of analgesic } \\
\text { use during preceding month } \\
(\text { mean } \pm \text { SD) }\end{array}$ & $5.7 \pm 7.1$ & $3.7 \pm 2.8$ & $3.6 \pm 2.4$ & 0.722 \\
\hline $\begin{array}{l}\text { Use of prophylactic medication, } \\
\text { n (\%) }\end{array}$ & $2(1.2)$ & $2(2.4)$ & 0 & \\
\hline Family history of migraine, $\mathrm{n}(\%)$ & $42(25.5)$ & $16(19.5)$ & $26(31.3)$ & 0.081 \\
\hline \multicolumn{5}{|l|}{ Self-reported comorbidities, n (\%) } \\
\hline $\begin{array}{l}\text { depression } \\
\text { bronchial asthma } \\
\text { hypertension } \\
\text { diabetes mellitus } \\
\text { heart disease }\end{array}$ & $\begin{array}{c}7(4.1) \\
6(3.5) \\
15(8.8) \\
11(6.4) \\
2(1.6)\end{array}$ & $\begin{array}{c}3(3.6) \\
3(3.6) \\
9(10.7) \\
6(7.1) \\
1(1.2)\end{array}$ & $\begin{array}{l}4(4.6) \\
3(3.5) \\
6(6.9) \\
5(5.6) \\
1(1.6)\end{array}$ & $\begin{array}{c}1.00 \\
1.00 \\
0.377 \\
0.710 \\
1.00\end{array}$ \\
\hline
\end{tabular}

Table 3. Outcome by treatment group (total days lost due to headache in the preceding 3 months, assessed by HALT)

\begin{tabular}{|l|c|c|}
\hline \multirow{2}{*}{ Visit } & \multicolumn{2}{|c|}{ Total days lost (mean \pm SD) } \\
\cline { 2 - 3 } & Control & Intervention \\
\hline Baseline & $12.4 \pm 11.0$ & $14.8 \pm 12.4$ \\
\hline After 3 months & $9.7 \pm 7.2$ & $10.7 \pm 7.6$ \\
\hline After 5 months & $5.2 \pm 2.8$ & $5.7 \pm 3.2$ \\
\hline
\end{tabular}

Table 4. Outcome by treatment group assessed by secondary measures

\begin{tabular}{|c|c|c|c|c|c|c|c|}
\hline \multirow{2}{*}{$\begin{array}{l}\text { Outcome } \\
\text { measure }\end{array}$} & \multicolumn{3}{|l|}{ Control } & \multicolumn{3}{|c|}{ Intervention } & \multirow[b]{2}{*}{ p: } \\
\hline & Baseline* & $\begin{array}{l}\text { After 3 } \\
\text { months** }\end{array}$ & $\begin{array}{l}\text { After 5 } \\
\text { months }^{\dagger}\end{array}$ & Baseline* & $\begin{array}{l}\text { After 3 } \\
\text { months** }\end{array}$ & $\begin{array}{l}\text { After 5 } \\
\text { months }^{\dagger}\end{array}$ & \\
\hline $\begin{array}{l}\text { Reporting } \\
\text { use of } \\
\text { abortive } \\
\text { medication } \\
\mathrm{n}(\%)\end{array}$ & $72(85.7)$ & $56(66.7)$ & $71(84.5)$ & $77(88.5)$ & $62(71.3)$ & $82(94.3)$ & 0.840 \\
\hline \multicolumn{8}{|c|}{ Change in HALT grades (\%) } \\
\hline $\begin{array}{l}\text { I }(0-5) \\
\text { II }(6-10) \\
\text { III }(11-20) \\
\text { IV }(>20)\end{array}$ & $\begin{array}{l}20.5 \\
12.1 \\
39.8 \\
27.7\end{array}$ & $\begin{array}{l}20.3 \\
20.3 \\
43.8 \\
15.6\end{array}$ & \begin{tabular}{|l|}
33.3 \\
51.1 \\
11.9 \\
0
\end{tabular} & $\begin{array}{l}17.2 \\
18.4 \\
19.5 \\
44.8\end{array}$ & $\begin{array}{l}20.0 \\
26.2 \\
32.3 \\
21.5\end{array}$ & $\begin{array}{l}27.8 \\
51.1 \\
20.0 \\
1.1\end{array}$ & 0.311 \\
\hline
\end{tabular}

* From a total of 159 observations recorded at baseline (missing 12); ** from a total of 121 observations recorded at 3 months (missing 50); ${ }^{\dagger}$ from a total of 168 observations recorded at 5 months (missing 3 ); $\$$ based on GEE comparing control and intervention groups for longitudinal change [19].

\section{Discussion}

In summary, we found improvement in both groups over 5 months of follow-up, consistent with effective (but not necessarily best) clinical management. This was reflected in the primary outcome measure and in reduction of HALT grades. All participating PCPs received training in the basic principles of diagnosing, classifying and managing headache disorders prior to study commencement, so any other finding would have been disappointing. However, against this background, any additional benefit from use of HURT (the specific intervention) was obscured.

Patients treated with HURT became significantly better able to understand their headache diagnoses over the follow-up period, replicating earlier findings [14]. The (English) wording of the question was "Do you feel you understand your diagnosis?", with response options "yes" or "no". Patients answering "no" (71\% of those responding at baseline) ought, according to the guidance in HURT, then to be given an explanation by their PCP, repeated if indicated during follow-up, so that "no" would become "yes". This appeared to happen in all but one case, but this was an uncontrolled observation: in the control group, the question was, of course, not put.

There are two methodological lessons from this study that make it worth reporting.

First, the study design was misconceived. HURT was designed as an aid for non-expert HCPs, guiding them to better outcomes [10-12]. Its development foresaw a scenario in which primary-care management of headache disorders was greatly expanded, with many HCPs untrained in this role and, consequently, likely to benefit from such guidance [12]. The training we gave our PCPs, in order to balance the treatment groups, was not in keeping with this scenario, and probably rendered HURT largely redundant as a management aid. Any future attempt empirically to demonstrate benefit from introducing HURT into primary-care headache management would do better to avoid preconditioning in this way. 
Khathaami AMA (2019) Does primary-care use of the HURT questionnaire aid the reduction of headache burden? Lessons for study design from an evaluation in primary care of the Arabic version

Second, the study demonstrates again the difficulty of conducting experiments of this sort in primary care. The study was terminated because of slow recruitment, with only $40 \%$ of the target achieved. PCPs with no special interest in headache disorders have no reason to be highly motivated in any form of headache research. There is no easy solution to this. Offering incentives (should resources allow) would, in all probability, have a similar conditioning effect.

In conclusion, this study failed in its purpose, but delivered helpful lessons for future study design in a difficult field of enquiry.

\section{Acknowledgements}

This work was supported by King Abdullah International Medical Research Centre.

We are very grateful to the participating PCPs and their patients.

\section{Authors' contributions}

AMK contributed to project design, data analysis and interpretation and drafting the manuscript. DA contributed to data collection, analysis review and drafting the manuscript. MAJ contributed to project design. NA contributed to data collection and drafting the manuscript. AK contributed to data analysis. TJS contributed to project design, data analysis and interpretation and drafting the manuscript. All authors reviewed manuscript drafts and approved the final version.

\section{References}

1. Stovner L, Hagen K, Jensen R, Katsarava Z, Lipton R, et al. (2007) The global burden of headache: a documentation of headache prevalence and disability worldwide. Cephalalgia 27: 193-210.

2. Vos T, Flaxman AD, Naghavi M, Lozano R, Michaud C, et al (2012) Years lived with disability (YLDs) for 1160 sequelae of 289 diseases and injuries 1990-2010: a systematic analysis for the Global Burden of Disease Study 2010. Lancet 380: 2163-2196.

3. Murray CJ, Vos T, Lozano R, Naghavi M, Flaxman AD, et al (2012) Disabilityadjusted life years (DALYs) for 291 diseases and injuries in 21 regions, 1990-2010: a systematic analysis for the Global Burden of Disease Study 2010. Lancet 380: 2197 2223.

4. GBD 2017 Disease and Injury Incidence and Prevalence Collaborators (2018) Global, regional, and national incidence, prevalence, and years lived with disability for 354 diseases and injuries for 195 countries and territories, 1990-2017: a systematic analysis for the Global Burden of Disease Study 2017. Lancet 392: 1789-1858. [Crossref]
5. Steiner TJ, Antonaci F, Jensen R, Lainez JMA, Lantéri-Minet M, et al. (2011) Recommendations for headache service organisation and delivery in Europe. $J$ Headache Pain 12: 419-426.

6. Steiner TJ (2004) Lifting the burden: the global campaign against headache. Lance Neurol 3: 204-205.

7. Steiner TJ (2005) Lifting The Burden: The Global Campaign to Reduce the Burden of Headache Worldwide. J Headache Pain 6: 373-377.

8. http://www.l-t-b.org

9. Steiner TJ, Birbeck GL, Jensen R, Katsarava Z, Martelletti P, et al. (2011) The Global Campaign, World Health Organization and Lifting The Burden: collaboration in action. J Headache Pain 12: 273-274.

10. Steiner TJ, Jensen R, Katsarava Z, Linde M, MacGregor EA, et al. (2019) Aids to management of headache disorders in primary care (2nd edition): on behalf of the European Headache Federation and Lifting The Burden: the Global Campaign against Headache. J Headache Pain 20: 57.

11. Buse DC, Sollars CM, Steiner TJ, Jensen RH, Al Jumah MA, et al. (2012) Why HURT? A review of clinical instruments for headache management. Curr Pain Headache Rep 16: $237-254$.

12. Steiner TJ, Buse DC, Al Jumah M, Westergaard ML, Jensen RH, et al. (2018) The headache under-response to treatment (HURT) questionnaire, an outcome measure to guide follow-up in primary care: development, psychometric evaluation and assessment of utility. J Headache Pain 19: 15

13. Rajeh SA, Awada A, Bademosi O, Ogunniyi A (1997) The prevalence of migraine and tension headache in Saudi Arabia: a community-based study. Eur J Neurol 4: 502-506.

14. Al Jumah M, Al Khathaami A, Tamim H, Al Owayed A, Kojan S, et al. (2013) HURT (Headache Under-Response to Treatment) questionnaire in the management of primary headache disorders: reliability, validity and clinical utility of the Arabic version. $J$ Headache Pain 14: 16. [Crossref]

15. Steiner TJ, Paemeleire K, Jensen R, Valade D, Savi L, et al. (2007) European principles of management of common headache disorders in primary care. $J$ Headache Pain 8 suppl 1: S3-S21.

16. International Headache Society Classification Subcommittee (2004) The International Classification of Headache Disorders. (2nd Edn) Cephalalgia 24 suppl 1: 1-160.

17. Steiner TJ, Lipton RB on behalf of Lifting The Burden: The Global Campaign against Headache (2018) The Headache-Attributed Lost Time (HALT) Indices: measures of burden for clinical management and population-based research. J Headache Pain 19: 12.

18. Choi BC, Pak AW (2005) A catalog of biases in questionnaires. Prev Chronic Dis 2: A13. [Crossref]

19. Ziegler A (2011) Generalized estimating equations. Springer.

Copyright: (C2019 Khathaami AMA. This is an open-access article distributed under the terms of the Creative Commons Attribution License, which permits unrestricted use, distribution, and reproduction in any medium, provided the original author and source are credited. 